\title{
OFF-PUMP CORONARY ARTERY BYPASS GRAFTING IN PATIENTS WITH OBESITY: COMBINED ANESTHESIA VERSUS TOTAL INTRAVENOUS ANESTHESIA
}

\section{Mikhail Turovets ${ }^{\bowtie} \mathbb{D}$, Alexander Popov (D), Andrej Ekstrem (D), Sergey Shlakhter, Anastasia Streltsova (1), Yuriy Vedenin (1)}

Volgograd State Medical University, Volgograd, Russia

turovets_aro@mail.ru

A B STRACT - Many researchers attribute obesity to an independent risk factor for perioperative complications of off-pump coronary artery bypass grafting (off-pump CABG). AIM. To conduct a comparative analysis of the early postoperative complications of off-pump CABG in obesity patients with with various types of anesthetic benefits. MATERIALS AND METHODS. A randomized study of the results of surgical treatment was carried out in obesity patients with coronary heart disease performing pump CABG. The study included 197 patients. The study group $(n=98)$ included patients who underwent combined anesthesia (with thoracic epidural analgesia (TEA)), and patients in the control group $(n=99)$ underwent total intravenous anesthesia (with opioids).

RESULTS. The use of combined anesthesia (with TEA) in patients with obesity significantly reduced the risk of developing new onset of renal dysfunction $(p=0.0180)$, respiratory complications $(\mathrm{p}=0.0177)$, atrial and ventricular arrhythmias ( $p=0.0029)$. We were less likely to diagnose other complications in patients of the study group, compared with patients in the control group: acute coronary syndrome ( $1.0 \%$ versus $3.0 \%, \mathrm{p}=0.3173)$, multiple organ failure syndrome ( $1.0 \%$ versus $3.0 \%, \mathrm{p}=0.3173)$, local infectious complications ( $1.0 \%$ versus $6.1 \%, p=0.0561)$. An uncomplicated early postoperative period was observed in $89.8 \%$ of patients in the study group and in $52.5 \%$ of patients in the control group $(\mathrm{p}=0.0000)$.

CONCLUSION. The use of combined anesthesia (with TEA) for off-pump CABG in patients with obesity reduces the risk of early postoperative complications, duration of hospitalization and stay in an intensive care unit.

KEY W ORDS — off-pump coronary artery bypass grafting, prevention of complication, obesity, thoracic epidural analgesia.

\section{INTRODUCTION}

Despite significant progress in the development of cardiac surgery associated with the advent of hightech equipment and modern supplies, to date, coronary artery bypass grafting $(\mathrm{CABG})$ is one of the most commonly used surgical methods for the treatment of patients with coronary heart disease (IHD) $[1,2,3]$.

But this surgical intervention in obese patients is associated with certain difficulties in surgical access, which often increases the time and trauma of the operation $[4,5]$. Some researchers attribute obesity to an independent risk factor for the development of perioperative complications of CABG due to unfavorable hormonal levels, metabolic disorders of glucose, lipids and purines, and changes in the hemostatic system $[4,5]$.

For a long time, studies are ongoing to reduce injuries of myocardial revascularization in patients of this category. It was possible to expand indications for CABG operations on a working heart (off-pump CABG), which would eliminate the risks associated with cardiopulmonary bypass $[6,7]$. But this tactic does not always bring the desired result in patients with obesity due to the often low contractile function of the left ventricle and multivascular damage to the coronary arteries [7]. In this regard, the search for new approaches to reducing the risk of complications after an off-pump CABG in patients of this category has not lost its relevance $[8,9,10,11]$.

In this regard, the aim of this study was a comparative analysis of the incidence of postoperative complications of off-pump CABG in patients with obesity with different types of anesthetic benefits.

\section{MATERIALS AND METHODS}

We conducted a randomized controlled trial of the results of surgical treatment of coronary heart disease in 200 patients with obesity who underwent coronary artery bypass grafting without cardiopulmonary bypass (off-pump CABG), from January 2015 to December 2019 at the bases of the Department of Anesthesiology and Resuscitation of Volgograd State Medical University. The type of anesthesiological aid was determined with a randomizing sign: combined (general anesthesia combined with thoracic epidural analgesia (TEA)) or total intravenous anesthesia. Randomization was carried out by the method of computer random sequence of numbers. Inclusion criterion: patients with obesity who underwent off-pump CABG. Exclusion criteria: performed on-pump CABG or there were absolute contraindications for TEA. Three patients were excluded from the study who underwent 
on-pump CABG due to clinical need. As a result, the study included the results of treatment of 197 patients.

The study was approved by the Volgograd Regional Independent Ethics Committee (IRB 00005839 IORG 0004900 [ref: 118/2014/12/05]). All patients received voluntary written informed consent to participate in the study and publish the results.

For the diagnosis of obesity, a body mass in$\operatorname{dex}$ (BMI) of $\geq 30 \mathrm{~kg} / \mathrm{m}^{2}$ was used. All subjects are divided into two groups. In the study group patients $(\mathrm{n}=98)$, combined anesthesia was used as an anesthetic aid: intravenous infusion of a propofol solution of $3-4 \mathrm{mg} / \mathrm{kg} \times$ hour, in combination with high thoracic epidural analgesia, which provided sensory block at the level Th I-X vertebrae. Epidural continuous infusion of solutions ropivacaine $0.3-0.5 \%$ $-6-7 \mathrm{ml} / \mathrm{h}$ with fentanyl $0.004-0.006 \mathrm{mg} / \mathrm{ml}$ was carried out. Puncture and catheterization of the epidural space was carried out 1 day before the operation. In patients of the control group $(\mathrm{n}=99)$, total intravenous anesthesia was used: intravenous infusion of propofol 3-4 mg/ $\mathrm{kg} \times$ hour in combination with continuous infusion of fentanyl solution $0.006-0.008 \mathrm{mg} / \mathrm{kg} \times$ hour. Induction of anesthesia was carried out by bolus intravenous injection of a solution of propofol $(2 \mathrm{mg} / \mathrm{kg})$, muscle relaxation was provided by depolarizing (solution of suxometonium chloride $1-1.5 \mathrm{mg} / \mathrm{kg}$ ) and non-depolarizing (solution of pipecuronium bromide $0.04-0.06 \mathrm{mg} / \mathrm{kg}$ ) muscle relaxants. Solution of fentanyl $(0.004-0.006 \mathrm{mg} / \mathrm{kg})$ was additionally bolus injected into the most traumatic stages of the operation (sternotomy, thoracotomy, cardiac enucleation).

In the early postoperative period, epidural analgesia continued for 72 hours in patients of the study group, and narcotic analgesics were used in patients of the control group. In all studied patients, postoperative analgesia was supplemented with the use of non-steroidal anti-inflammatory drugs (lornoxicam 8 $\mathrm{mg} \times 2$ times a day or ketorolac $30 \mathrm{mg} \times 3$ times a day). In the postoperative period, the diagnosis of acute coronary syndrome (ACS) took into account patient complaints, the appearance or expansion of zones of hypokinesis (according to echocardiography), an increase in ischemic changes on the electrocardiography, an increase in markers of myocardial necrosis (creatine phosphokinase-MB, troponin-T). The syndrome of multiple organ failure was established with failure in three or more body systems. New onset renal dysfunction was established with an increase in blood plasma creatinitis by $2 \mathrm{mg} / \mathrm{dl}$ or more. Atrial and ventricular arrhythmias were considered if they lasted 24 hours or more. Respiratory complications were recorded when confirmed by X-ray data.
As shown in Table 1, according to demographic and operational data, the comparison groups were comparable (by sex and age, duration of surgery and the number of shunts imposed, patients' comorbid state $(\mathrm{p}>0.05))$.

All findings were processed by means of variation statistics methods using the STATISTICA 10.0 software. The statistical processing was performed using the Mann-Whitney U-test and $\chi^{2}$ Pearson. The difference was considered significant at the significance level of more than $95 \%(\mathrm{p}<0.05)$.

\section{RESULTS AND DISCUSSION}

Patients in the control group required longer invasive respiratory support than patients in the study group $(5.3 \pm 0.8$ vs $3.6 \pm 0.9$ hours $(p=0.0274))$. In the study group there were significantly more patients who did not need invasive respiratory support $(8.2 \%$ vs $1.0 \%$ in the control group $(\mathrm{p}=0.0162))$ and significantly fewer patients with invasive respiratory support lasting more than 6 hours (14.3\% versus $28.3 \%$ in the control group $(p=0.0165))$. In the early postoperative period, patients of the control group had a shorter duration of adrenergic agonist therapy (AAT), but this decrease was not significant $(\mathrm{p}=0.5715)$.

Researchers compared other postoperative parameters of the study groups (Table 1 ). It was found that the use of combined anesthesia (with TEA) in obese patients significantly reduced the risk of developing new onset renal dysfunction ( $\mathrm{p}$ $=0.0180)$, respiratory complications $(p=0.0177)$, atrial and ventricular arrhythmias $(\mathrm{p}=0.0029)$. In patients with the study group, there was one case of the development of ventilator-associated pneumonia, and in the control group this complication was recorded in eight patients. We were less likely to diagnose other complications in patients of the study group, compared with patients in the control group: acute coronary syndrome ( $1.0 \%$ vs $3.0 \%, \mathrm{p}=0.3173)$, multiple organ failure syndrome ( $1.0 \%$ versus $3.0 \%$, $\mathrm{p}=0.3173)$, local infectious complications (1.0\% vs $6.1 \%, p=0.0561$ ). An uncomplicated early postoperative period was observed in $89.8 \%$ of patients in the study group and in $52.5 \%$ of patients in the control $\operatorname{group}(\mathrm{p}=0.0000)$.

The use of combined anesthesia reduced the median time from surgery to discharge from the hospital by $51.7 \mathrm{~h}$. In the study group, as compared to the control group $(215.8 \mathrm{~h}$ in control and $164.1 \mathrm{in}$ study group $\mathrm{p}=0.0419)$. The treatment time in the intensive care unit also significantly decreased $(65.6 \mathrm{~h}$ in control and $44.2 \mathrm{~h}$ in study group $(\mathrm{p}=0.0229))$.

Hospital mortality in the study group and in the control group was 1.0\% (1/98) and 2.0\% (2/99), 
Table 1. Comparison of patient demographics and various operative and postoperative parameters

\begin{tabular}{|c|c|c|c|}
\hline Study parameters & Study group $(n=98)$ & Control group $(n=99)$ & $P$ \\
\hline \multicolumn{4}{|l|}{ Demographic profile: } \\
\hline Male, $n(\%)$ & $54(55,1)$ & $56(56,6)$ & 0,8361 \\
\hline Age (mean $\pm S D)$ & $62,1 \pm 8,3$ & $61,8 \pm 9,1$ & 0,4931 \\
\hline$\leq 65$ лет, n (\%) & $52(53,1)$ & $58(58,6)$ & \multirow{2}{*}{0,4350} \\
\hline > 65 лет, n (\%) & $46(46,9)$ & $41(41,4)$ & \\
\hline BMI (mean $\pm S D)$ & $34,1 \pm 3,3$ & $35,8 \pm 3,1$ & 0,3718 \\
\hline Hypertension, n (\%) & $58(59,2)$ & $61(61,6)$ & 0.7271 \\
\hline $\mathrm{DM}, \mathrm{n}(\%)$ & $44(44,9)$ & $50(50,5)$ & 0,4308 \\
\hline COPD, n (\%) & $14(14,3)$ & $12(12,1)$ & 0,6536 \\
\hline Renal dysfunction, n (\%) & $8(8,2)$ & $6(6,1)$ & 0,5658 \\
\hline $\mathrm{CCl}, \mathrm{n}(\%)$ & $27(27,6)$ & $32(32,3)$ & 0,4647 \\
\hline \multicolumn{4}{|l|}{ Operative parameters: } \\
\hline Operation duration (mean $\pm S D)$ & $259,3 \pm 72,4$ & $254,6 \pm 68,3$ & 0,7185 \\
\hline Bypass 1, n (\%) & $8(8,2)$ & $11(11,1)$ & 0,4834 \\
\hline Bypass 2, n (\%) & $69(70,4)$ & $65(65,7)$ & 0,4746 \\
\hline Bypass 3, n (\%) & $21(21,4)$ & $23(23,2)$ & 0.7612 \\
\hline \multicolumn{4}{|l|}{ Postoperative parameters: } \\
\hline Extubation, $h,($ mean $\pm S D)$ & $3,6 \pm 0,9$ & $5,3 \pm 0,8$ & $0,0274^{*}$ \\
\hline No ventilation, $\mathrm{n}(\%)$ & $8(8,2)$ & $1(1,0)$ & $0,0162^{*}$ \\
\hline Up to 3 hours, n (\%) & $18(18,4)$ & $6(6,1)$ & $0,0083^{*}$ \\
\hline $3-6$ hours, $n(\%)$ & $58(59,2)$ & $64(64,6)$ & 0,4298 \\
\hline More than 6 hours, $n(\%)$ & $14(14,3)$ & $28(28,3)$ & $0,0165^{*}$ \\
\hline$A A T, h,($ mean $\pm S D)$ & $13,3 \pm 7,6$ & $12,7 \pm 6,7$ & 0,5715 \\
\hline No therapy, $\mathrm{n}(\%)$ & $12(12,2)$ & $10(10,1)$ & 0,6329 \\
\hline Up to 6 hours, $n(\%)$ & $26(26,5)$ & $28(28,3)$ & 0,7828 \\
\hline 6-12 hours, $\mathrm{n}(\%)$ & $32(32,7)$ & $37(37,4)$ & 0,4874 \\
\hline More than 12 hours, $n(\%)$ & $28(28,6)$ & $24(24,2)$ & 0,4907 \\
\hline New onset renal dysfunction, $n$ (\%) & $2(2,0)$ & $10(10,1)$ & $0,0180^{*}$ \\
\hline $\mathrm{ACS}, \mathrm{n}(\%)$ & $1(1,0)$ & $3(3,0)$ & 0,3173 \\
\hline Respiratory complications, n (\%) & $1(1,0)$ & $8(8,1)$ & $0,0177^{*}$ \\
\hline Atrial and ventricular arrhythmias, $\mathrm{n}(\%)$ & $4(4,1)$ & $17(17,2)$ & $0,0029^{*}$ \\
\hline Multiple organ failure syndrome, $n(\%)$ & $1(1,0)$ & $3(3,0)$ & 0,3173 \\
\hline Local infectious complications, n (\%) & $1(1,0)$ & $6(6,1)$ & 0,0561 \\
\hline ICU stay, h (mean \pm SD) & $44,2 \pm 6,4$ & $65,6 \pm 7,3$ & $0,0229^{*}$ \\
\hline Hospital stay, h (mean \pm SD) & $164,1 \pm 31,3$ & $215,8 \pm 37,1$ & $0,0419^{*}$ \\
\hline Mortality, $\mathrm{n}(\%)$ & $1(1,0)$ & $2(2,0)$ & 0,5667 \\
\hline
\end{tabular}

Note: ${ }^{*} P<0.05$, statistically significant; $I C U$ — Intensive Care Unit; BMI — Body mass index; DM — Diabetes mellitus; COPD — Chronic obstructive pulmonary disease; $\mathrm{CCI}$ - Chronic cerebral ischemia; $A A T$ — Adrenergic agonist therapy; ACS — Acute coronary syndrome; SD — Standard deviation.

respectively. The cause of death was multiple organ failure syndrome in $100 \%$ of cases.

Patients in the control group had higher intraoperative consumption of narcotic analgesics and intravenous anesthetics (by $36.7 \%$ and $29.6 \%$, respectively). This affected the lengthening of the required time for invasive respiratory support, which was accompanied by an increase in the incidence of ventilator-associated pneumonia in the early postoperative period.

The decrease in the incidence of postoperative complications associated with the use of TEA can be explained by a more effective decrease in the severity of the operational stress response and endothelial dysfunction, improved perfusion of the operative zone 
and the prokinetic effects of TEA, and an increase in the quality of postoperative analgesia. A significant decrease in the incidence of respiratory complications, atrial and ventricular arrhythmias in patients of the study group is probably due to a decrease in the duration of invasive respiratory support (due to a decrease in the dose of narcotic analgesics) and sympathetic blockade accompanying TEA.

Due to the small sample size of this study, in some cases there were no statistically significant differences in patients in the incidence of the most common complications of CABG. In this regard, for inclusion in the wide clinical practice of the proposed method, confirmation of the results by large randomized trials is required.

\section{CONCLUSION}

The use of combined anesthesia (with TEA) for off-pump CABG in patients with obesity reduces the risk of early postoperative complications, the duration of hospitalization and the duration of treatment in the intensive care unit.

\section{CONFLICT OF INTERESTS.}

The authors state that they have no conflict of interests.

\section{Contributors}

MIT and AMS collected, analysed, and interpreted data and made the figures. ASP did the literature review and collected data. AVE and YuIV collected data and made the figures. MIT and SMS interpreted and analysed the data. MIT, ASP, AVE, SMS, YuIV and AMS prepared the manuscript for submission.

\section{REFERENCES}

1. ESC/EACTS Guidelines on myocardial revascularization: the Task Force on Myocardial Revascularization of the European Society of Cardiology (ESC) and the European Association for Cardio-Thoracic Surgery (EACTS). Developed with the special contribution of the European Association of Percutaneous Cardiovascular Interventions (EAPCI). European Journal of Cardio-Thoracic Surgery. 2014; 46(4): 517-592. doi: $10.5167 /$ uzh-106697

2. Abuanzeh R., Al Shawabkeh Z., Al-Edwan H. Is redo coronary artery bypass graft in patients over 70 years old safe? Journal of the Royal Medical Services. 2016; 23(3): 49-54. doi: 10.12816/0029073

3. Wang Y., Wen M., Zhou J. et Al. Coronary artery bypass grafting versus percutaneous coronary intervention in patients with noninsulin treated type 2 diabetes mellitus: A meta-analysis of randomized controlled trials. Diabetes/Metabolism Research and Reviews. 2017; 34(1): e2951. doi: 10.1002/dmrr.2951

4. Ao H., Wang X., Xu F. et al. The impact of body mass index on short- and long-term outcomes in patients undergoing coronary artery graft bypass. PLoS One. 2014; 9(4): e95223. doi: 10.1371 / journal. pone.0095223

5. MA W.Q., SUN X.J., WANG Y. eT AL. Does body mass index truly affect mortality and cardiovascular outcomes in patients after coronary revascularization with percutaneous coronary intervention or coronary artery bypass graft? A systematic review and network meta-analysis. Obes Rev. 2018;19(9):1236-1247. doi: $10.1111 /$ obr. 12713

6. Alwaqf N, Khader Y, Ibrahim K. Coronary artery bypass: predictors of 30 -day operative mortality in Jordanians . Asian Cardiovascular and Thoracic Annals. 2012; 20(3): 245-251. doi: 10.4021/jocmr1020w

7. Moller C.H., Perko M.J., Lund J.T. et al. Three year follow-up in a subset of high-risk patients randomly assigned to off-pump versus on-pump coronary artery bypass surgery: The best bypass surgery trial. Heart. 2011; 97:907-913. doi: 10.1136/ hrt.2010.211680

8. Ghali A., Al-Banna A., Balbaa Ye., Sami G., AlAnsary A., Kamal A., Sengab H. Coronary bypass surgery in patients aged 70 years and over: Mortality, morbidity, \& length of stay. Dar al-fouad experience. The Egyptian Heart Journal. 2014; 66(1): 6. doi: 10.1016/j.ehj.2013.12.017

9. Rong H., Changsheng M., Shaoping N. Effect of metabolic syndrome on prognosis of revascularization in patients with coronary artery disease. Heart. 2010; 96(3): A116-A117. doi: 10.1136/ hrt.2010.208967.376

10. Shroyer A.L., Grover F.L., Hattler B. et al. On-pump versus off-pump coronary-artery bypass surgery. The New England Journal of Medicine. 2009; 361: 1827-1837. doi: 10.1056/NEJMoa0902905

11. Ekstrem A.V., Turovets M.I., P.V. Mozgovoi P.V., Popov A.S., LopushKov A.V. Prevention of complications for coronary artery bypass surgery in the elderly. Sovremennyye problemy nauki i obrazovaniya. 2018; 5: URL: http://www.scienceeducation.ru/article/view?id=2817. doi:10.17513/ spno. 28174 [In Russ.]. 